\title{
The design of compassionate care
}

\begin{abstract}
Aims and objectives The aim of this paper is to investigate the tension between individual and organisational responses to contemporary demands for compassionate interactions in health care.
\end{abstract}

Background Health care is often said to need more compassion among its practitioners. However, this represents a rather simplistic view of the issue, situating the problem with individual practitioners rather than focusing on the overall design of care and health care organisations, which have often adopted a production-line approach.

Design This is a position paper informed by a narrative literature review.

Methods A search of the PubMed, Science Direct and CINAHL databases for the terms compassion, care and design was conducted in research literature published from 2000 through to mid-2013.

Results There is a relatively large literature on compassion in health care, where authors discuss the value of imbuing a variety of aspects of health services with compassion including nurses, other practitioners and, ultimately, among patients. This contrasts with the rather limited attention that compassionate practice has received in health care curricula and the lack of attention to how compassion is informed by organisational structures and processes. We discuss how making the clinic more welcoming for patients, promoting bidirectional compassion and compassion formation in nursing education can be part of an overall approach to the design of compassionate care.

Conclusions We discuss a number of ways in which compassion can be enhanced through training, educational and organisational design, through exploiting the potential of brief 
opportunities for communication, and initiatives involving patients and service users, as well as practitioners and service leaders.

Relevance to clinical practice The development of contemporary health care systems could usefully address the overall design of compassionate care rather than blame individual practitioners for a lack of compassion.

Keywords: care, compassion, organisational design, position paper, review 


\title{
Summary: What does this paper contribute to the wider global clinical community?
}

- When considering compassion, we should consider not only the compassionate qualities of individual practitioners, but the overall design of heath care systems as a whole.

- Managers and policymakers, as well as professional bodies could do more to foster compassion by considering these broader organisational issues.

\begin{abstract}
Aims
This paper aims to investigate how compassion is conceived of in the literature on health care and explore the tension between individual and organisational responses to contemporary demands for compassionate practice in health care. We will do this by exploring the literature on compassion and organisational design as well as contemporary policy documents and inquiry reports, with a view to identifying recommendations for service delivery.

\section{Background}

There is an emerging consensus that compassion in health and social care is desirable, but as yet it is less clear how compassion is conceived of in this field, and how it may be enhanced through education, training, cultures of practice and organisational design.

Therefore in this paper we will examine how the problem of compassion has been formulated in the literature on nursing and critically examine the assumptions which much of this writing embodies. Rather than superimpose our own definition of compassion we will instead explore how it has been defined and formulated by others and suggest ways in which the concept can be extended to encompass a more systemic understanding of compassion in its socio-political and organisational context.
\end{abstract}


Compassion within health care and in the practice of its professionals is increasingly seen as desirable (Martinsen 2006, Shields \& Wilkins 2006, Darzi 2008, Firth-Cozens \& Cornwell 2009, Gilbert 2009, Graber \& Mitcham 2009, Care Quality Commission 2011, Crawford 2011, Crawford \& Hallawell 2011, Crawford et al. 2011, Nauert 2011, Parliamentary and Health Service Ombudsman 2011, Cornwell 2012, Cummings \& Bennett 2012, Royal College of Nursing 2012, Crawford et al. 2013). In the UK, a key policy emphasis has been that 'high quality care should be as safe and effective as possible, with patients treated with compassion, dignity and respect' (Darzi 2008, p. 11). This move to revisit the place of compassion in health services has been driven, in part, by a succession of woeful events in care delivery that can be considered complacent at best, and criminal at worst. For example, in the United Kingdom alone, there have been well-publicised cases of abuse at Winterbourne View, a private care home, and at Mid-Staffordshire National Health Service (NHS) Foundation Trust, where the Robert Francis Inquiry found a lack of compassion among other failures (Francis 2013). Such events are not unique to the United Kingdom and can be found around the world (Friele et al. 2008, Greenberg et al. 2010). There is now a sense of urgency to address the lack of compassion that has been identified in modern health services. Despite a body of theory on compassion and a focus on personal and person-centred care in nursing theory and models (Brykczyńska 1996, Watkins 2000, Chambers \& Ryder 2009, McCormack \& McCance 2010), compassion has as yet rarely featured in books on nursing theory (Reed et al. 2004, Kim \& Kollak 2006). Whilst there are exhortations to practitioners to practice with greater compassion, there is currently very little in the way of a formalised framework or set of approaches to compassionate practice in modern health care, with its demanding environments and time-sensitive targets and processes. 
In this paper therefore, we will examine the contradiction between individual and organisational responses to contemporary demands for compassionate interactions in nursing and wider health care. Although Bjerknes and Bjørk (2012) found that newly graduated nurses are likely to enter nursing practice experience with empathy for their patients and enthusiasm for their profession, they face a context of organisational and professional limitations that hinders their performance. This finding raises concern about how well student nurses are socialised in compassionate practice (Sawatzky et al. 2009, Curtis et al. 2012) and highlights the need to develop cultures of compassion (Richardson 2004).

Compassionate care is foregrounded in relation to many patient groups, for example, in palliative care, care of older people, children and individuals with mental health problems (Betcher 2010, Wasserman \& McNamee 2010, Insel 2012). Straughair (2012a, 2012b) argued that 'compassion in nursing can be attributed to the Christian ideals translated by Florence Nightingale into the characterization of the professional nurse' (2012a, p. 163).

Despite the value imputed to compassion, and the value nursing theory often attaches to the quality of relationships between nurses and patients, as Allen (2004) has pointed out, there is often a discrepancy between aspirations and practice. The desire for a model of care based on emotional intimacy with patients is often confronted with the reality of a nursing role which largely revolves around mediating between different occupational groups and ideologies instead. Even in the contemporary era, the focus on compassion has tended to prioritise the qualities of the nurse rather than the nature of the organisational context. For example Bradshaw (2011) called for compassionate and skilled nurses to meet the needs of patients and presented three key principles for nursing, based on historical analysis, which can be related to the modern nursing situation: (a) the character of the nurse, (b) competence in knowledge and skills and (c) ward leadership. She suggested that a reappraisal of nursing history could be a resource for a new vision of health care that meets the needs of patients for 
compassionate and skilled care internationally. However, to ensure that nurses in the future are able to deliver compassionate care, any focus on character, knowledge, skills and effective leadership will need to be met by corporate strategies that take into consideration environment, processes, human resources, skill mix and workload. In addition, the educators of health care personnel must be mindful of implementing appropriate recruitment and selection strategies, involving service users and embedding the concept of compassion and practical steps to demonstrating compassion in nursing curricula.

There is little direction as to how nurses can use and apply theories of compassion and compassionate care in contemporary health-care settings, which often limit or restrict human interaction within a production-line approach to service. A number of critics of health care systems have identified the preoccupation with service standards (Ballatt and Campling, 2011) or the marketization and privatisation of health care, combined with command and control models of management as restricting the opportunities for caring, compassionate practice (Pollock, 2005, Seddon, 2008). These two tendencies toward encouraging compassion on the one hand and toward business-style modes of management on the other, can often appear to be in opposition. The desire to enable compassion is often at odds with the perceived need to optimise the use of resources and encourage time efficient care. In an attempt to resolve this dilemma we propose that modern health care systems can be best served by addressing the overall design of compassionate care and the services within which it operates. This approach entails moving away from the simplistic blaming of individual practitioners for their lack of compassion and mandating a full recognition of how organisations can bring about changes to the production-line health-care environment and its processes so as to facilitate compassionate relationships. Finally, we will suggest ways in which compassionate design of health care can be approached. 


\section{Design and methods}

This position paper is informed by a search of PubMed, Science Direct and CINAHL databases for the terms compassion, care and design, which was conducted in research literature published from 2000 through to mid-2013. The research literature was augmented with salient earlier literature of leading theorists or commentators. We included only those papers that were published in English. In addition, the paper is informed by writing on the compassion, usually in book form, as well as inquiry reports and policy materials where these have addressed compassion and cognate issues. Reading the literature independently and collectively enabled the authors to identify several key themes, which were used as an initial framework for coding the material, and which were further consolidated as this coding scheme was applied more systematically on subsequent passes through the literature. Below, we detail the key findings, and lead into some rather less well trodden paths which are so far only hinted at in the literature for promoting compassion and making clinical environments emotionally warmer for all stakeholders.

\section{Findings}

\section{Defining compassion}

Although the word compassion is defined in many slightly different ways, in the majority of cases where it appears in the literature of nursing the focus is on individual emotional, attitudinal and cognitive factors. Broadly, it is formulated as involving an awareness of or sensitivity to the pain or suffering of others that results in taking verbal, non-verbal or physical action to remove, reduce or alleviate the impact of such affliction. This encompasses the openness of attention, awareness of suffering, motivation and action found in much psychological literature on the subject (Gilbert, 2009). Whether or not individuals show compassion, therefore, is seen as dependent on their ability to develop a 'compassionate 
mentality'. There are a range of attributes that can be applied here, as identified by Crawford et al. (in press) (Table 1):

[Insert Table 1 here]

These attributes of a compassionate mentality indicate the richness and complexity of compassion. Writing from a Buddhist tradition, Feldman and Kuyken (2011, p. 143) noted the following:

Compassion is a multi-textured response [italics added] to pain, sorrow and anguish. It includes kindness, empathy, generosity and acceptance. The strands of courage, tolerance, equanimity are equally woven into the cloth of compassion. Above all compassion is the capacity to open to the reality of suffering and to aspire to its healing.

Kindness, in particular, seems to be a core concern; however, even this characteristic is far from simple and might include the following:

sympathy, generosity, altruism, benevolence, humanity, compassion, pity, empathy and that in the past were known by other terms as well, notably philanthropia (love of mankind) and caritas (neighbourly or brotherly love). The precise meaning of these words vary, but basically they all denote what the Victorians call 'open heartedness,' the sympathetic expansiveness linking of self to other. (Phillips \& Taylor 2009, p. 4)

Similarly, in their major systematic review of the term compassion and its evolutionary origins and functions, Goetz et al. (2010) clustered 'compassion' with 'sympathy', 'empathy' and 'kindness'. The related term kindness, is defined by Ballatt \& Campling (2011, p. 4) as 'something that is generated by an intellectual and emotional understanding that self-interest and the interests of others are bound together'. 


\section{Compassion as a mental state and orientation}

Thus, compassion is, in the views outlined above, conceptualised as a mental state and orientation. An important strand of investigation has sought to identify personal traits that seem to be associated with greater compassion. For example an early study by Carmel and Gilk (1996) found that younger physicians held more pro-social attitudes and were more empathic, showed greater evidence of compassion. Jang (2012) identified that among public servants compassion was greater among those scoring higher on self-report measures of agreeableness and conscientiousness (from Costa and McRae's 'big five' model of personality (1992)). Caring for others - provided that it does not exceed the resources that one has, and is voluntary - can have positive effects on mental health. People can feel real joy from working hard and seeing others benefit (Schwartz et al. 2003). Research has shown not only that compassion can become a part of a self-identity, but also that it can be linked to self-image goals such that individuals act compassionately so as to be liked or to be compliant (Crocker \& Canevello 2008). In Crocker and Canevello’s study of US college students, having compassion-focused self-identity goals was associated with feelings of closeness, connectedness and social support, and inversely related to conflict, loneliness and a feeling of being afraid and confused by emotions. By contrast, self-image goals showed the reverse relationships. Thus, where compassion is engaged in for reasons associated with selfimage, for example acting with compassion in order to be liked or to appear compliant may not yield benefits. In a health care context, compliance with guidelines can involve superficial behaviour and does not necessarily mean that the actor will be fully engaged with the value of caring for others, or with putting the patient at the centre of the interaction. With a top-down approach, governments tend to focus more on compliance than responsibility taking (Seddon, 2008). In this paper, we are more concerned with social facilitators of compassion and of how health services, rather than individual practitioners, need to respond. 


\section{Why compassion is limited}

In much of the material surveyed for this paper, the problem of limitations in compassion and compassion depletion in health care is viewed simplistically as a problem with individual nurses. In other words, it is seldom viewed as a failure in the design of care organisations themselves. Saliently, this individual focus is particularly acute in policy documents. For example, Cummings and Bennett, writing for the UK's Department of Health, describe the staff's 'professional instincts for compassion' (Cummings and Bennett, 2012, p. 12). Individual practitioners, or their respective professional bodies and training programmes, are blamed for a failure in compassionate care rather than attention being focused on the threat culture of production-line, metrics-obsessed modern health-care delivery that often results in 'cold clinics' - that is, clinical spaces that generate little relational warmth (Crawford \& Brown, 2011). This threat culture is driven by discourses of insecurity - namely, having to deal with the consequences of failing to meet targets, fulfilling the need to audit clinical work intensively, underpinning practice with an evidence base, managing with low staff levels and other resources and, most of all, working under the eye of the clock.

Associated with this individual focus was an interest in the interpersonal factors which might inhibit its expression. For example, major inhibitors of compassion included threats and stress, especially threats that compel individuals to focus on self-defence. When caregiving is felt to be obligatory in some way, or the need of the other exceeds the resources the caregiver wants to put into caring, caring can be stressful and detrimental to the caregiver's health (Vitaliano et al. 2003). With regard to other inhibitors, research has revealed that when humans are oriented by anger or vengeance, compassionate mental states tend to be inhibited. Excessive stress is believed to induce compassion fatigue (Figley 1995, Rothschild \& Rand 2006), which results in reduced attention to distress, such that stressed individuals rushing between different tasks may not notice distressed patients, a numbing of 
motivation and less vigorous helpful actions. Other experiences to which health practitioners are vulnerable include burnout or cynicism - that is, the belief that nothing makes that much difference (Benson and Magraith, 2005). Therefore, these different mental states make activating compassion difficult. Understanding the facilitators and inhibitors of mental states that an individual experiences is therefore important.

Compassion research (Gilbert, 2009) has articulated various ways in which threat system processing can interfere with compassion processing. Organisations can create a sense of threat and then try to cope with threat in a variety ways, all of which can inhibit compassion. For example, continually informing people about financial restrictions, the need for savings and potential job losses is hardly conducive to instilling a sense of security. Organisations that focus on cutting front-line staff create a sense of threat and low morale (Seddon, 2008). Equally, as organisation theorists have long noted, in circumstances of threat and uncertainty there is a good deal of pressure in an organisation towards self-examination, accountability and reporting structures (Warwick et al, 1975). As Brown et al (2011) point out, in large organisations individuals are increasingly unlikely to have autonomy. Yet there is a substantial body of literature to suggest that autonomy in the workplace increases productivity, morale and commitment (Chirkov et al, 2010). Systems and organisational cultures, then, can do a great deal to facilitate experiences of threats or support, which in turn facilitate different mental states in the workplace.

\section{Policy and organisational approaches}

A number of important policy documents concerned with compassion in care adopt a determinedly individualistic focus. For example, the consultation document Developing the Culture of Compassionate Care: (Cummings \& Bennett 2012) stresses individualised accountability for this component of clinical delivery, with individual practitioners or professional training being the key elements in delivery. Consequently an opportunity has 
been missed to consider the compassionate design of health systems as a whole. The role of governments and organisations that design the spaces and contexts for compassionate engagements to occur between patients and practitioners - the question of 'compassionate design' (Crawford, 2011), in other words - is given little attention. The challenge is to develop an approach which considers systematically the organisational and architectural design of services so as to maximise the likelihood of compassionate engagement. Compassion is not some kind of ointment to be applied by smiling health practitioners, nor is it something that can be absorbed as a 'skill' through linear curricula. Cornwell (2012) offered the following explanation:

Nurses, midwives and care-givers look after patients in the context of organisations, not in isolation. It's simply not possible to deliver reliable, compassionate care 24/7 unless the system as a whole makes it a priority and the most powerful people in the system actively demonstrate their commitment to the values and behaviours that support caring. (Cornwell, 2012, para. 4)

Yet from the point of view of health care practitioners themselves, it regularly seems as if it is frontline staff such as nurses who are scapegoated (Smith, 2013). In the UK context, some commentators, such as Andrew Burnham MP have alleged, this kind of framing denigrates front line practitioners and public provision and prepares the ground for private provision to be presented as the solution (Hansard, 13 May 2013, column 356). If the problem is formulated in individual, terms, then, it may lead to particular political consequences for the future of statutory health provision where individuals are scapegoated rather than organisations being carefully examined.

Time for compassion? 
Commentators on the UK's statutory health care sector have pointed to the way it resembles a production line (e.g. Burnham, 2013, Chalice, 2007). Practitioners and patients find themselves in organisational cultures which emphasise threat or blame, which itself is likely to result in higher rates of error in care (Khatri et al, 2009). The experience of threat may also result in compassion fatigue and depletion, or even lead to deterioration in care (Gilbert 2009; Collins and Long, 2003). This is at odds with long-standing philosophies of health care which emphasise humane and compassionate values (Fulford et al, 2012). Effectiveness and efficiency in health care could be compatible with compassion; yet the way this is implemented has often been felt to damage practitioners and patients in the current factorystyle, conveyor belt health service. This 'production-line mentality' (Crawford \& Brown 2011) is so prominent that it is not unusual to hear nurses speaking more like factory supervisors. Indeed, in a recent study on 'cleanliness talk', modern matrons used phrases befitting the factory floor: 'You know it's very much like a conveyer belt'; 'turnover is very quick'; 'you haven’t got enough time between patients to process'; 'it's a very quick turnaround' (Crawford et al. 2011).

\section{Remedies for compassion depletion}

In modern health services, where time and money are dominant concerns, how can nurses be more compassionate to themselves, their colleagues and, ultimately, their patients? Martinsen described the modern health-care situation as follows:

Productivity, efficiency, cost-benefit-analyses, classification knowledge, and a specific professional language where we may fetch everything out of the computer, are words, concepts and phenomena which better describe the health service of today....We have to provide quick knowledge, it must at least be applied quickly. (Martinsen, 2006, p. 101) 
Modern health services mirror the wider 'blip culture' (Toffler, 1981) and 'social acceleration' (Rosa \& Scheuerman 2009) such that practitioner time is often parcelled out sparingly against the clock (Deacon \& Fairhurst 2008). Health care is very time intensive. Indeed, one of the most important qualities that staff and patients value is time for listening and sharing key information and perspectives on health conditions (Stickley and Freshwater, 2006). There is a great deal of anecdotal evidence from general practitioner (GP) practices through all aspects of health care that one of the major changes in the last 10 years has been a severe curtailment of listening time. In a recent study on the language used by practitioners when talking about compassion in acute mental health care, one of the highest frequency words was time (Crawford et al. 2013). This finding raises the following question: How can health care practitioners move forward to deliver a compassionate service in the workplace? Moreover, if this is to occur, it must do so in spite of this compression of time into small chunks or blips and despite what Bang (2011: 434) calls the subordination of public services to a coercive, hierarchical authority which drains them of their communicative and interactive powers.

\section{Warming up the clinic}

It is our belief that local, creative, simple 'decompressing' changes can be made to 'warm up the clinic' and make clinical settings more welcoming, thereby contributing to a compassionate design for health-care services. The emphasis on tasks being done against the clock or the excuse of being 'far too busy' should not blind health care providers to opportunities for advancing compassionate spaces and processes that encourage compassionate relationships, and to make use of even the brief time available to convey or demonstrate compassion. Contrary to prominent models of communication derived from counselling theory that advance extended 'time-greedy' communication so as to develop a 
'therapeutic relationship', the realities of fast-paced modern health care require new approaches. Crawford et al. (2006) and Brown et al. (2006) outlined a new approach to health communication that seeks to work within time limitations yet still advance compassionate practice: Brief, Ordinary and Effective (BOE) Model for Health Communication. The BOE model illustrates how compassionate communication can be effected in fast-paced health-care contexts and how support and affirmation of patients can be conveyed at the same time as other activities.

Crawford and Hallawell (2011) posed the following question about core values and compassionate practice: 'Where is the love?' It is possible for health care workers to apply this question to their work in health-care services and clinical areas and to their regard for patients and other staff members. In attempting to answer this question, practitioners can find ways to improve the affective quality of their work and, in so doing, promote 'hominess' the comforts of home - (Martinsen, 2006: 48) in the clinic for the benefit of both practitioners and patients. As Thrift (2004) suggested, affective response is something that can be designed into built spaces. Moreover as Kanov et al. (2004) propose, when members of the organisation jointly notice and address the distress of others it becomes a collective response which can inform the organisation's entire culture, and be propagated among its members.

Front line practitioners can play a key role in delivering hominess. However, such work is not simply the business of nurses, for as we have argued, providing compassionate care involves the design of services as a whole. Compassion is achieved in and by government and health-care organisations. It is therefore also the responsibility of managers and governing bodies for health-care delivery to cohere vision and resources for delivering the 'warm clinic' and promote an inclusive ethics in the design of the organisations they manage (Gleeson and Kearns, 2001). 
New possibilities: Bidirectional compassion and architecture of care

In our opinion, policymakers and managers need to promote what we have termed bidirectional compassion - that is, compassion towards both staff and patients - such that spaces, processes and resources that are compassionate to practitioners are encouraged. This demonstration of compassion toward practitioners will in turn make them better able to exhibit compassion in their approach to patients. Patients who are treated with compassion show compassion for hard-pressed practitioners and practitioners may then show compassion for managers and so on.

Promoting bidirectional compassion requires much more than a call for compassion among nurses and other health professionals or personnel. The concept of bidirectional compassion must be incorporated into the complete architecture of care and its processes so as to advance low-threat and supportive spaces for human compassion to thrive. When calling for what she calls 'hominess' in clinical settings, Martinsen (2006) insisted that the architecture (where one 'dwells'), space and time of health care create particular lived experiences involving the giving and receiving of care. This echoes the key conclusions of the initial Robert Francis Inquiry into the poor care provided at Mid Staffordshire NHS Trust in the United Kingdom, contained in the following comment, which reinforces the idea of how the design, organisation and delivery of the whole service around compassion help to improve care performance:

People must always come before numbers. Individual patients and their treatment are what really matters. Statistics, benchmarks and action plans are tools not ends in themselves. They should not come before patients and their experiences. This is what must be remembered by all those who design and implement policy for the NHS. (Francis, 2010: 4). 
It is time for the concept of hominess to become central to the creation of enhanced care environments, policies and practices, that is, compassionate design. More than ever, the health-care system needs to undergo a full review and to develop a strategy for achieving a successful, compassionate 'architecture' of care. In particular, health service management bodies that deliver services designed to be compassionate for both patients and practitioners need to be identified and celebrated. This full review of the health-care system needs to take into consideration the following questions: Where are the beacons for a more sophisticated and honest appraisal of compassion depletion? How might leaders of nursing and those of the other health-care professions jointly develop compassionate health care without taking a simplistic approach and blaming poor individual performance for any failures that occur? When will leaders in modern health care call for a greater emphasis on evidence-based management (rather than evidence-based practice) in the delivery of compassion-promoting environments and processes, not least by countering a threat culture?

\section{Compassion formation}

Compassionate design cannot occur without professional education first being addressed. Those responsible for education need to consider how compassion formation takes place in a way that is not simply limited to exploring values or communication skills of the practitioner but rather involves a deeper understanding of how other contexts of health care may lead to compassion depletion and how a more effective architecture of care can be advanced. The new public management thinking of the past few decades has affected educational systems and national health services worldwide, leading to changes in learning environments and nursing education curricula (Karseth, 2006). For example Kvangarsnes (2005) found that the Norwegian national curriculum for nursing education in 2000 had become standardised through the use of more bureaucratic and academic language and design rather than allowing 
space for humane or compassionate practice. This description of nursing, however, has little in common with the kind of philosophy of care that Martinsen (2006) has put forward. There seems to be a need to develop curricula with a stronger emphasis on how nurses can contribute in creative and practical ways to the compassionate design of interventions, processes and spaces.

\section{Conclusions}

The idea that compassion is inhibited by various threat factors such as stress, time pressures, bureaucracies, a greater emphasis on quantity rather than quality, a shift in focus from input to output, currently receives only limited support because of the lack of relevant research available (Seddon, 2008). Yet there are a growing number of examples which, taken together, help to support our concern that these factors have a pernicious influence on the interpersonal quality of care for both patients and practitioners. For example, in a study of early career nurses by Horsburgh and Ross (2013) participants felt that their agency as compassionate professionals was stifled by the structure of the organisation. Severn et al (2012) found that time pressure and management were among the factors associated with compassion fatigue and burnout among audiologists.

The accumulating evidence about organisational factors in compassion fatigue means that the task of organisational design to facilitate beneficial engagement between staff and patients is all the more urgent. Policy makers and managers might usefully turn their attention to formulating a vision for compassionate culture in health care so as to involve authorship on the part of all key professional leads in the organization. To aid this process, leaders might prioritise and promote the development of high-quality, evidence-based care environments 
and processes that reduce threat and advance bidirectional compassion, as well as reward excellence and leadership in creating compassionate spaces, processes and regard for others.

There are already a variety of initiatives where organisational activities are adapted to facilitate greater compassion. For instance, Goodrich (2012) describes an initiative to use socalled 'Schwartz Center rounds' - a system that allows staff to get together once a month to share stresses and dilemma associated with caring for patients. Malterud et al (2009) describe the value of practitioners recognising and sharing their own and their clients' vulnerabilities and difficulties. Reynolds (2009) describes how a project with black and minority ethnic mental health service users promoted kindness, friendliness and even the availability of preferred skin and hair care products. Even so, the majority of ideas and activities concern the immediate interface between practitioners and patients rather than the overall system in which health care is embedded. The acknowledgement of how systems and structures can impede compassion is under way, but considerably less is known about how organisations can promote it.

The process of enabling compassion on the part of practitioners can also be facilitated through physical and organisational design. For example, the creation of well-resourced, attractive respite zones near clinical areas where practitioners can recover, or by building into the organisation's processes regular review of the communication performance of clinicians via supervisor and patient/service user evaluations (Mills et al, 2002).

Clinical leaders, educators and individual practitioners can optimise the use of warm, compassionate interactional styles, even when time is limited. Consideration of how this can be achieved is already underway, for example through the development of the notion of Brief, 
Ordinary and Effective (BOE) interaction (Crawford et al, 2006) that affirms others, especially in busy, time-pressured clinical environments. In connection with this it would be valuable to incorporate teaching on compassionate communication and how space and time can influence the nature and value of interactions. In this way it might be possible to develop 'compassion formation' as an integral part of health care practitioner training, enabling future practitioners to review critically and assist in the design, management and practice of compassionate care.

\section{Relevance to clinical practice}

In light of our discussion, we propose that compassionate health care practice is clearly situated within an overall framework of compassionate care design, which incorporates actions at policy, organisational, individual and educational levels rather than seeing it as merely being about the individual performance of nurses.

A critical aspect of compassionate design could be the implementation of changes to the physical environment, the language and culture, as well as work processes so as to reduce the prominence of production-line and threat mentalities. The physical design of the workplace can contribute to this through the provision of spaces and processes that are more likely to generate hominess, that is, emotionally warm as opposed to 'cold clinics'

This involves much more than working from a patronising mnemonic of $6 \mathrm{Cs}-$ care, compassion, competence, communication, courage and commitment as in Cummings and Bennett's (2012) recently published consultation document Developing the Culture of Compassionate Care. Although the recent focus on compassionate care is welcome, health care organisations need to build much more robustly on Cumming's and Bennett's reference 
to 'supporting positive staff experience' and their call for nurses to be 'supported by organisations that promote compassionate and caring culture and values'.

By contrast, the notion of compassionate design facilitates a closer examination of how the built environment, processes and culture of care can be shaped to counter threat cultures and afford our nurses with a context that promotes compassionate mentalities and acts. In our opinion, reducing the threat posed by a production-line mentality, with its instrumentality and time obsession, may rehumanise health care. 


\section{References}

Allen, D (2004) Re-reading nursing and re-writing practice: towards an empirically based reformulation of the nursing mandate, Nursing Inquiry, 11, 4, 271-283.

Ballatt, J \& Campling, P (2011) Intelligent Kindness: Reforming the Culture of Healthcare. London: Royal College of Psychiatrists.

Bang, HR (2011) The politics of threats: late-modern politics in the shadow of neoliberalism, Critical Policy Studies, 5, 4, 434-448.

Benson, J \& Magraith, K (2005) Compassion fatigue and burnout: The role of Balint groups, Australian Family Physician, 34, 6, 497-498.

Betcher, DK (2010) Elephant in the room project: improving caring efficacy through effective and compassionate communication with palliative care patients. MEDSURG Nursing, 19, 101-105.

Bjerknes, MS \& Bjørk, IT (2012) Entry into nursing: an ethnographic study of newly qualified nurses taking on the nursing role in a hospital setting. Nursing Research and Practice, 690348. doi:10.1155/2012/690348.

Bradshaw, A (2011) Editorial: the future of clinical nursing: meeting the needs of patients for compassionate and skilled nurses? Journal of Clinical Nursing, 20, 1797-1800.

Brown, B, Crawford, P \& Carter, R (2006) Evidence-Based Health Communication.

Buckingham: Open University Press.

Brown, P, Lauder, H \& Ashton, D (2011) The Global Auction The Broken Promises of Education, Jobs, and Incomes, New York: Oxford University Press.

Brykczyńska, GM (1996) Caring: The Compassion and Wisdom of Nursing. London: Hodder Arnold. 
Burnham, A (2013) Too many hospitals operate a production line model, The Telegraph, 21 July 2013 p. 25.

Care Quality Commission (2011) Dignity and Nutrition. Inspection Programme: National Overview. Newcastle Upon Tyne: Care Quality Commission.

Carmel, S, \& Gilk, SM (1996) Compassionate-empathic physicians: Personality traits and social-organizational factors that enhance or inhibit this behavior pattern, Social Science and Medicine, 43, 8, 1253-1261.

Chalice, R (2007) Improving healthcare using Toyota lean production methods, Milwaukee: American Society for Quality Press.

Chambers, C \& Ryder, E (2009) Compassion and Caring in Nursing. Oxford: Radcliffe.

Chirkov, VI, Ryan, R \& Sheldon, KM (2010) Human Autonomy in Cross-Cultural Context: Perspectives on the Psychology of Agency, Freedom, and Well-Being, New York: Springer.

Collins, S, and Long, A (2003) Too tired to care? The psychological effects of working with trauma, Journal of Psychiatric and Mental Health Nursing, 10, 17-27.

Cornwell, J (2012) Developing a culture of compassionate care. Available at:

http://www.kingsfund.org.uk/blog/2012/10/developing-culture-compassionate-care (accessed 10 October 2012).

Costa, PT, Jr. \& McCrae, RR (1992) Revised NEO Personality Inventory (NEO-PI-R) and NEO Five-Factor Inventory (NEO-FFI) manual. Odessa, FL: Psychological Assessment Resources.

Crawford, P (2011) NHS failures in care for the elderly demand prompt remedies. Letter to the Editor. The Times, Friday, 14 October 2011, p. 35.

Crawford, P \& Brown, B (2011) Fast healthcare: brief communication, traps and opportunities. Patient Education \& Counseling, 82, 3-10. 
Crawford, P, Brown, B \& Bonham, P (2006) Communication in Clinical Settings.

Cheltenham: Nelson Thornes.

Crawford, P, Gilbert, P, Gilbert, J \& Gale C (2011) The language of compassion. Taiwan International ESP Journal, 3, 1-16.

Crawford, P, Gilbert, P, Gilbert, J, Gale, C \& Harvey, K (2013) The language of compassion in acute mental health care. Qualitative Health Research, (in press).

Crawford, P \& Hallawell, B (2011) Where is the love? Learning Disability Practice, 14, 9.

Crocker, J \& Canevello, A (2008) Creating and undermining social support in communal relationships: the role of compassionate and self-image goals. Journal of Personality and Social Psychology, 95, 555-575.

Cummings, J \& Bennett, V (2012) Developing the Culture of Compassionate Care: Creating a New Vision for Nurses, Midwives and Care-Givers. London: Department of Health.

Curtis, K, Horton, K \& Smith, P (2012) Student nurse socialisation in compassionate practice: a Grounded Theory study. Nurse Education Today, 32, 790-795.

Darzi, A (2008) High Quality Care for All: NHS Next Stage Review Final Report. London: Department of Health.

Deacon, M \& Fairhurst, E (2008) The real-life practice of acute inpatient mental health nurses: an analysis of 'eight interrelated bundles of activity'. Nursing Inquiry, 15, 330-340. Feldman, C \& Kuyken, W (2011) Compassion in the landscape of suffering. Contemporary Buddhism, 12, 143-155.

Figley, CR (1995) (editor). Compassion Fatigue: Coping with Secondary Traumatic Stress Disorder in Those Who Treat the Traumatized. New York: Brunner/Mazel. Firth-Cozens, J \& Cornwell, J (2009) The Point of Care: Enabling Compassionate Care in Acute Hospital Settings. London: King's Fund. 
Francis, R (2010) Independent Inquiry into Care Provided by Mid Staffordshire NHS Foundation Trust, January 2005-March 2009, Vol 1. London: The Stationery Office. Francis, R (2013) Report of the Mid Staffordshire NHS Foundation Trust Public Inquiry, London: The Stationery Office.

Friele, DR, Sluijs, MEM \& Legemaate, J (2008) Complaints handling in hospitals: an empirical study of discrepancies between patients' expectations and their experiences. $B M C$ Health Services Research, 8, 199.

Fulford, KWM, Peile E, and Carrol H (2011) Essential values-based medicine: linking science with people. Cambridge: Cambridge University Press.

Gilbert, P (2009) The Compassionate Mind. London: Constable Robinson.

Gleeson, B \& Kearns, R (2001) Remoralising landscapes of care, Environment and Planning D: Society and Space, 19, 61-80.

Goetz, JL, Keltner, D \& Simon-Thomas, E (2010) Compassion: an evolutionary analysis and empirical review. Psychological Bulletin, 136, 351-374.

Goodrich, J (2012) Supporting hospital staff to provide compassionate care: Do Schwartz Center Rounds work in English hospitals? Journal of the Royal Society of Medicine, 105, $117-122$.

Graber, DR \& Mitcham, MD (2009) Compassionate clinicians: exemplary care in hospital settings. In The Science of Compassionate Love: Theory Research, and Application (Fehr C, Sprecher S \& Underwood LG editors), Chichester, Wiley, Chichester, pp. 345-372. Greenberg, GL, Battles, BJ \& Haskell, H (2010) Learning from patients’ experiences: enhancing patient safety event reporting systems. Cirugía y Cirujanos, 78, 460-465. Horsburgh, D \& Ross, J (2013) Care and compassion: the experiences of newly qualified staff nurses, Journal of Clinical Nursing, 22, 1124-1132. 
Insel, TR (2012) Compassionate allowance for people with schizophrenia? Schizophrenia Research, 140, 15-16.

Jang, CL (2012) The Effect of Personality Traits on Public Service Motivation: Evidence from Taiwan, Social Behaviour and Personality: An international Journal, 40, 5, 725-733. Kanov, JM, Maitlis, S, Worline, MC, Dutton, JE, Frost, PJ \& Lilius, JM (2004) Compassion in organizational life, American Behavioral Scientist, 47, 6, 808-827.

Karseth, B (2006) Curriculum restructuring in higher education after the Bologna Process: a new pedagogic regime? Revista Española de Educación Comparada, 12, 255-284.

Khatri, N, Brown, GD \& Hicks, LL (2009) From a blame culture to a just culture in health care. Health Care Management Review, 34, 4, 312-22.

Kim, HS \& Kollak, I (2006) (editors). Nursing Theories: Conceptual and Philosophical Foundations. New York: Springer.

Kvangarsnes, M (2005) Sjukepleiarutdanning i endring. Nasjonalt rammeplanarbeid 19922004 med fokus på styring, profesjonar, diskursar og tekst (Changes in nursing education. National curriculum development 1992-2004 with focus on steering, professions, discourses and text). Doctoral Thesis NTNU 2005:76.

McCormack, B \& McCance, T. (2010) Person-Centred Nursing: Theory and Practice. Chichester: Wiley-Blackwell.

Malterud, K, Fredriksen, L \& Gjerde, MH (2009). When doctors experience their vulnerability as beneficial for the patients, Scandinavian Journal of Primary Health Care, 27: $85-90$.

Martinsen, K (2006) Care and Vulnerability. Oslo: Akribe.

Millis, SR, Jain, SS, Eyles, M, Tulsky, D, Nadler, S, Foye, PM, Elovic, E \& DeLisa, JA (2005) Assessing physician's interpersonal skills: do patients and physicians see eye-to-eye? American Journal of Physical Medicine and Rehabilitation, 81, 946-951. 
Nauert, R. (2011) Compassion missing in American health care. PsychCentral. Available at: http://psychcentral.com/news/2011/09/09/compassion-missing-in-american-healthcare/29295.html (accessed 31 August 2012).

Parliamentary and Health Service Ombudsman (2011) Care and Compassion? Report of the Health Service Ombudsman on Ten Investigations into NHS Care of Older People. London: The Stationery Office.

Phillips, A \& Taylor, B (2009) On Kindness. London: Hamish Hamilton Press.

Pollock, AM (2005) NHS PLC: The privatisation of our health care, London: Verso.

Reed, PG, Shearer, NBC \& Nicholl, LH (2004) (editors). Perspectives on Nursing Theory, 4th edn. Philadelphia: Lippincott Williams \& Wilkins.

Reynolds, D (2009) Human kindness, compassion and love: the hospital ward visiting scheme designed and delivered by Canerows and Plaits, Mental Health and Social Inclusion, $14,3,6-9$.

Richardson, A (2004) Creating a culture of compassion: developing supportive care for people with cancer. European Journal of Oncology Nursing, 8, 293-305.

Rosa, H \& Scheuerman, WE (2009) High-Speed Society: Social Acceleration, Power, and Modernity. University Park, PA: Pennsylvania State University Press.

Rothschild, B \& Rand, M (2006) Help for the Helper: The Psychophysiology of Compassion Fatigue and Vicarious Trauma. New York: W. W. Norton.

Royal College of Nursing (2012) Quality with Compassion: The Future of Nursing Education. Report of the Willis Commission on Nursing Education, 2012. London: Royal College of Nursing on behalf of the independent Willis Commission on Nursing Education. Sawatzky, JAV, Enns, CL, Ashcroft, TJ, Davis, PL, Harder, BN (2009) Teaching excellence in nursing education: a caring framework. Journal of Professional Nursing, 25, 260-266. 
Schwarz, C, Meisenhelder, JB, Ma, Y \& Reed, B (2003) Altruistic social interest behaviours are associated with better mental health, Psychosomatic Medicine, 65, 778-785.

Seddon, J (2008) Systems Thinking in the Public Sector: The Failure of the Reform

Regime.... and a Manifesto for a Better Way. London: Triarchy Press.

Severn, MS, Searchfield, GD \& Huggard, P (2012) Occupational stress amongst audiologists:

Compassion satisfaction, compassion fatigue, and burnout, International Journal of

Audiology, 51: 3-9.

Shields, M \& Wilkins, K (2005) Findings from the 2005 National Survey of the Work and

Health of Nurses. Ottawa: Statistics Canada, Ottawa.

Smith, P (2013) Counter the scapegoating and show the public you still care, Nursing Times, 109, 6, 11 .

Straughair, C (2012) Exploring compassion: implications for contemporary nursing. Part 1.

British Journal of Nursing, 21, 160-164.

Straughair, C (2012) Exploring compassion: implications for contemporary nursing. Part 2.

British Journal of Nursing, 21, 239-244.

Stickley, T and Freshwater, D (2006) The art of listening in the therapeutic relationship, Mental Health Practice, 9, 5, 12-18.

Thrift, N (2004) Intensities of feeling: towards a spatial politics of affect. Geografiska Annaler, Series B, 86, 57-78.

Toffler, A (1981) The Third Wave. London: Bantam Books.

Vitaliano, PP, Zhang, J \& Scanlan, JM (2003) Is caregiving hazardous to one's physical health? A meta-analysis. Psychological Bulletin, 129, 946-972.

Warwick, DP, Meade, M \& Reed, T (1975) A theory of public bureaucracy, Cambridge: Harvard University Press. 
Wasserman, IC, \& McNamee, S (2010) Promoting compassionate care with the older people: a relational imperative. International Journal of Older People Nursing, 5, 309-316. Watkins, P (2000) Mental Health Nursing: The Art of Compassionate Care. Oxford: Butterworth-Heinemann, 2000. 
Table 1 Attributes of a 'compassionate mentality'

\begin{tabular}{cc} 
Kind & Concerned \\
Gentle & Empathetic \\
Warm & Friendly \\
Loving & Tolerant \\
Affectionate & Patient \\
Caring & Supportive \\
Sensitive & Encouraging \\
Helpful & Non-judgemental \\
Considerate & Understanding \\
Sympathetic & Giving \\
Comforting & Soothing \\
Reassuring & Validating \\
Calming & Attentive \\
Open & Respectul \\
\hline
\end{tabular}

Note. From 'The Language of Compassion in Acute Mental Health Care', by P Crawford, P Gilbert, J Gilbert, C Gale \& K Harvey, 2012, Qualitative Health Research. Copyright 2012 by P Crawford. Reprinted with permission. 